\title{
Comparison Exam of Gallahue's Hourglass Model and Clark and Metcalfe's the Mountain of Motor Development Metaphor
}

\author{
Sayed Kavos Salehi*, Mahmoud Sheikh, Fatemeh Sadat Talebrokni \\ Department of Motor Behavior, Faculty of Physical Education and Sport Sciences, University of Tehran, Tehran, Iran \\ Email: ^Sk.salehi@yahoo.com
}

How to cite this paper: Salehi, S. K., Sheikh, M., \& Talebrokni, F. S. (2017). Comparison Exam of Gallahue's Hourglass Model and Clark and Metcalfe's the Mountain of Motor Development Metaphor. Advances in Physical Education, 7, 217-233. https://doi.org/10.4236/ape.2017.73018

Received: May 2, 2017

Accepted: July 7, 2017

Published: July 10, 2017

Copyright @ 2017 by authors and Scientific Research Publishing Inc. This work is licensed under the Creative Commons Attribution International License (CC BY 4.0).

http://creativecommons.org/licenses/by/4.0/ (c) (i) Open Access

\begin{abstract}
With regards to the fact that motor development can be conceptualized and analyzed by theoretical view, the authors' main purpose of this article was to compare Gallahue's triangulated hourglass model with Clark and Metcalfe's the mountain of motor development metaphor. These are two common devices for understanding both product and process of motor development. By using the dynamic systems, Gallahue likened the human motor development to a triangulated hourglass. Clark and Metcalfe also have analogy of this process to a mountain that includes six periods in development of motor skills. The current research method was descriptive-analytical, in which by in-depth study and interpretation of available information and analytical review, we evaluated, compared and explained the similarities and differences between two mentioned conceptual views. The results showed, more of the concepts discussed in the mountain of motor development metaphor are adaptable to Gallahue's hourglass model, with this difference that the formulation, drawing shapes of movements and development conceptualization is more regular and realistic in the hourglass model. Overall, the Gallahue's hourglass model and Clark and Metcalfe's conceptual metaphor have a large overlap and are important to facilitate understanding and provide a theoretical framework of the process and product of motor development.
\end{abstract}

\section{Keywords}

Compensation, Hourglass Model, Metaphor, Model, Motor Development, Theoretical View

\section{Introduction}

The model is a framework and structure that arose in the special field, devel- 
oped, and then used in another area. This model is the analogy or metaphor that conducts research and thinking. For example, in experimental studies, nervous system is likened to a telephone system or eye is likened to the camera. Models enable us to more fully understand complex concepts, and ultimately, testing the model can further enhance our knowledge and understanding of our own behavior (Payne \& Isaacs, 2011). Hourglass model is a heuristic device, that is, a conceptual metaphor, or model of motor development, that provides us with general guidelines for describing and explaining motor behavior. Heuristics are general rules providing one clues for how to search for answers to given problems. In the study of development, many theories use heuristic devices that researchers hope will eventually lead to algorithms, that is, set of rules guaranteed that if followed, will lead to finding a solution to the given kind of problem (Gallahue, Ozmun, \& Goodway, 2012).

According to Clarke and Metcalfe, metaphor is often the closest analogy of a representation (image), and therefore compared to the model, has less formalization (logic), and is more of a guess and conjecture. Despite these modest differences, the purposes of the metaphor and a model are similar in that they seek to explain while offering the possibility of advancing understanding and knowledge. Metaphor enables us to discover process of motor development, and thus makes us capable of teaching and learning in the area of human motor development .The metaphor is not the end of all explanation for motor development, but researchers consider it as a starting point for discussing, explaining and even testing (Payne \& Isaacs, 2011).

David L. Gallahue (1998), based on the ecological perspective, with an emphasis on three factors: individual features, environment and task and having accurate understanding of movements and stages of development, likened the process of motor development to an hourglass that has four phases, which include: reflexive movement phase, rudimentary movement phase, fundamental movement phase, and specialized movement phase. Each phase includes several stages. Phases and stages in this model have an overlap, That is, before the complete end of the one phase (or stage), begins the next phase (or the next stage). In this model, approximate age for each phase and stage is drawn. The age range of each period, depends on the experimental conditions and the genetic structure of individual, therefore, may be a difference in different individuals.

Following this, Clark and Metcalfe (2002) in the mountain of motor development metaphor, compared motor development to learning to climb a mountain. Like human motor development, the process takes years, is a sequential and cumulative process, and is strongly affected by the personal skills and traits the individual climber eventually brings to the mountain. It is also a nonlinear process. Like climbing a mountain, human motor development is characterized by progression, sometimes followed by regression, only to progress again later in life. The ascent and elevation one achieves on the mountain can be compared to acquiring higher levels of motor skill. Achieving more mature levels of motor 
development is a continuous interaction between the climber and his or her climbing skills (the individual) and the mountain (the constantly changing environmental conditions on the mountain and as we pass through life). Arriving at the top of the mountain can also be construed as the ultimate attainment of movement proficiency, highly skilled movement ability. In short, the mountain portrays the "lifelong, cumulative, and progressive adaptation" that we see in our own motor development as we pass through life (Clark \& Metcalfe, 2002). The ascent up the mountain includes passage through six periods of human motor development: the reflexive period, the preadapted period, the fundamental patterns period, the context-specific period, the skillful period, and the compensation period. Each period contribute to the acquisition of skills necessary for the next. In addition, the time spent in each period of development varies for each individual while being highly dependent on factors like the amount of experience or instruction, quality of instruction, and inherent individual qualities (such as height, strength, movement speed) that govern motor skill acquisition. Development is a function of adaptations throughout life as we learn to integrate our personal structural and functional characteristics with our environment. Finally, in the mountain of motor development metaphor, considerable preparation and preplanning must go into the ascent (Payne \& Isaacs, 2011).

In current study, in order to introduce a best integrated framework to determine the product and the process of motor development, and clarifying similarities and differences of theoretical discussions about motor development, we have compared these two specific theoretical glances to the process of human motor development.

\section{The First Period of the Gallahue's Hourglass Model and Clark and Metcalfe's the Mountain of Motor Development Metaphor}

Both in the hourglass model and metaphor of motor development, the first period called reflexive period. Reflex, is sudden and involuntary movement that appears in response to a specific stimulus.These behaviors are controlled by the lower centers of the brain such as the spinal cord and brain stem (Haywood \& Getchell, 2014). According to Gallahue, the reflexive phase of motor development may be divided into two overlapping stages called information encoding and decoding stage (see Figure 1).

The information encoding stage of the reflexive movement phase is characterized by observable involuntary movement activity during the fetal period until about the fourth month of infancy. During this stage lower brain centers are more highly developed than the motor cortex and are essentially in command of fetal and neonatal movement. These brain centers are capable of causing involuntary reactions to a variety of stimuli of varying intensity and duration. Reflexes at this point serve as the primary means by which the infant is able to gather information, seek nourishment, and find protection through movement. 


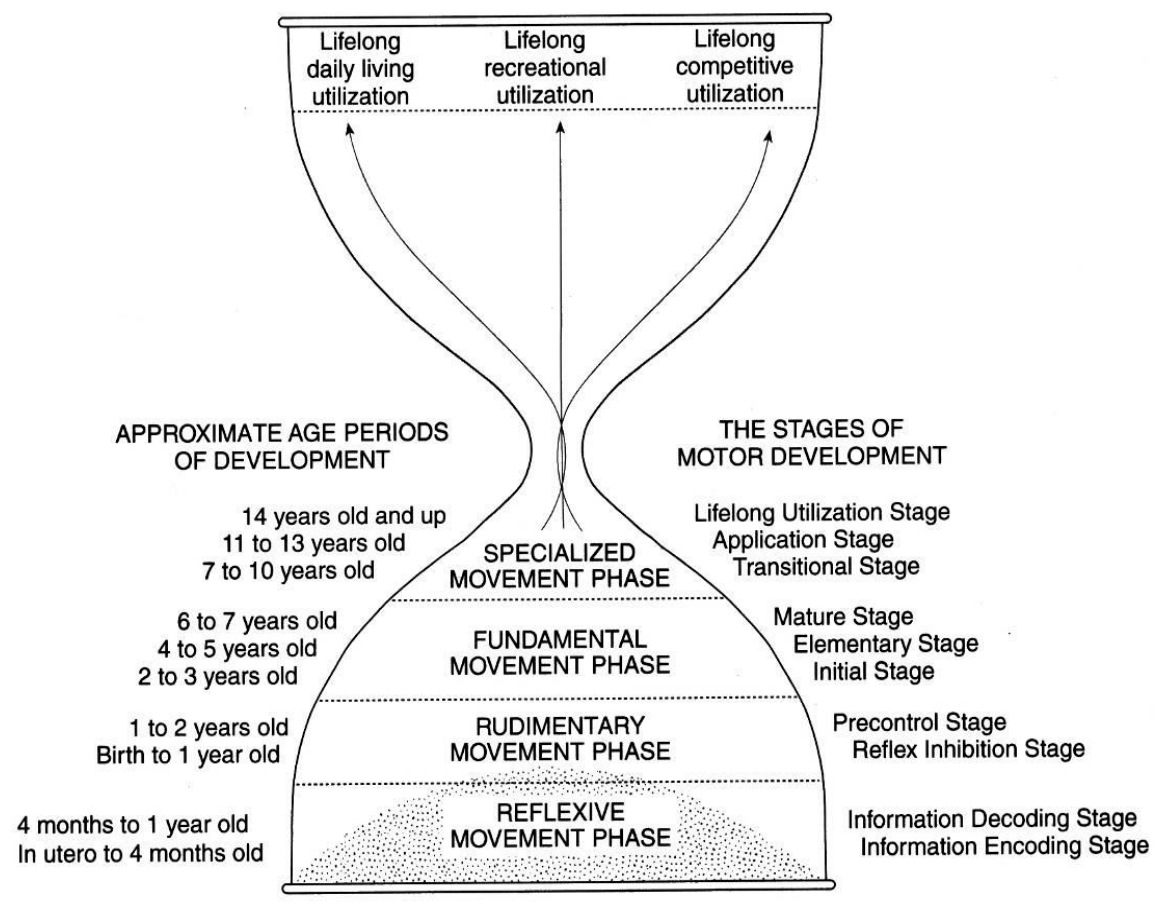

Figure 1. Gallahue's hourglass model (Gallahue, Ozmun, \& Goodway, 2012).

The information decoding (processing) stage of the reflex phase begins around the fourth month. During this time there is a gradual inhibition of many reflexes as higher brain centers continue to develop. Lower brain centers gradually relinquish control over skeletal movements and are replaced by voluntary movement activity mediated by the motor area of the cerebral cortex. The decoding stage replaces sensorimotor activity with perceptual-motor ability. That is, the infant's development of voluntary control of skeletal movements involves processing sensory stimuli with stored information, not merely reacting to stimuli (Gallahue, Ozmun, \& Goodway, 2012).

Clark and Metcalfe have introduced reflexive period in a similar way. According to them, this period is characterized by the individual's beginning to learn the ways of the world and includes the last third, approximately three months, of the prenatal state as well as the initial weeks following birth, even though many infant reflexes will continue to flourish throughout the first year or more of life. This period is essential for survival (protection, nourishment, and so on), and cognitive (intellectual) and motor development. They state that although these infant reflexes initiate and facilitate the infant's interactions with the world, they can impede future development if they endure too long. In normal, healthy infants these reactions gradually "disappear" across the first year of life. In children who are developmentally delayed, these reflexes can persevere, slowing the normal rate of development (Payne \& Isaacs, 2011).

On this basis, concepts and theoretical issues related to the first stage of human development in the hourglass model and the mountain of motor development are largely compatible with each other. 


\section{The Second Period of the Gallahue's Hourglass Model and Clark and Metcalfe's the Mountain of Motor Development Metaphor}

Gallahue has called the second stage of human motor development as rudimentary movement phase and Clark and Metcalfe called preadapted period. Rudimentary movements are the first forms of voluntary movement that are seen in the infant beginning at birth to about age 2 . The nature of these is maturationally determined and is characterized by a highly predictable sequence of appearance. This sequence is resistant to change under normal conditions. The rate at which these abilities appear will vary from child to child, however, and depends on biological, environmental, and task factors. Gallahue explains that childhood voluntary movement are known rudimentary movements, because they are the basic form for more advanced movement in the later, and are divided into three categories includes: stability movements such as gaining control of the head, neck, and trunk muscles; the manipulative tasks of reaching, grasping, and releasing; and the locomotor movements of creeping, crawling, and walking. The rudimentary movement phase of development may be subdivided into two stages that represent progressively higher orders of motor control.

The reflex inhibition stage of the rudimentary movement phase continues from birth to about age 1 . In this stage, development of the cortex, and lessening of certain environmental constraints, causes several reflexes to be inhibited and gradually disappear. Primitive and postural reflexes are replaced by voluntary movement behaviors. At the reflex inhibition level, voluntary movement is poorly differentiated and integrated because the neuro-motor apparatus of the infant is still at a rudimentary stage of development. Movements, though purposeful, appear uncontrolled and unrefined. If the infant wishes to make contact with an object, there will be global activity of the entire hand, wrist, arm, shoulder, and even trunk. The process of moving the hand into contact with the object, although voluntary, lacks control.

The pre-control stage of the rudimentary movement phase is determined by around 1 to 2 year of age. Around 1 year of age, children begin to bring greater precision and control to their movements. The process of differentiation between sensory and motor systems and integrating perceptual and motor information into a more meaningful and congruent whole takes place. The rapid development of higher cognitive processes and motor processes encourages rapid gains in rudimentary movement abilities during this stage. During the pre-control stage, children learn to gain and maintain their equilibrium, to manipulate objects, and to move throughout the environment with an amazing degree of proficiency and control considering the short time they have had to develop these abilities. The maturational process may partially explain the rapidity and extent of development of movement control during this phase, but the growth of motor proficiency is no less amazing. Overall, at this stage as a result of perceptual and cognitive development, movements are performed with control, proficiency and precision (Gallahue, Ozmun, \& Goodway, 2012). 
Clark and Metcalfe in explaining the second period of the mountain of motor development state that the term preadapted refers to the emergence of voluntary movements and the control of reflexes. These researchers explain that the term preadapted is selected to depict the emergence of our motor skill as we overcome the early constraints (such as genetic limitations, gravitational forces, and environmental limitations) on our movement and learn to function in our gravity-bound environment. As part of this process, we gradually gain increasingly independent function, including an ability to move somewhat selectively throughout our space. Through a progression of movement behaviors that often begin with maintaining control of our own head and neck, we gradually gain greater control of the upper body, hips, legs, and feet until we can sit, stand, and walk independently. Similarly, during this period, reaching and grasping behaviors emerge as a part of an intricate interaction between our gradually developing postural ability, an evolving interaction between arm and hand actions, and our visual control. Clark and Metcalfe (2002) state that the preadapted period is culminated by our ability to feed ourselves and initial attempts at walking. Obviously, self-feeding is greatly dependent on our emerging eye-hand coordination, just as walking is dependent on our evolving postural control.

With regard to the topics mentioned above, it appears that most of the concepts discussed in the preadapted period of the mountain of motor development are compatible with rudimentary movement phase of hourglass model, with this difference that the formulation and depict of movement shapes in the hourglass model is more regular and realistic.

In Gallahue's hourglass model, the rudimentary movement phase is divided into three categories including stability movements, locomotor movements and manipulation movements, but in the second period of the mountain of motor development, the same movements are mentioned in an irregular manner and without specific category. On the other hand, in the hourglass model, the end of the rudimentary movement phase is in the 2 years old, but in the mountain of motor development, authors mentioned that the preadapted period is culminated by our ability to feed ourselves and initial attempts at walking. Thus, it seems the supposed age range of rudimentary movement phase in the hourglass model is more than the age range of preadapted period proposed by the mountain of motor development.

\section{The Third Period of the Gallahue's Hourglass Model and Clark and Metcalfe's the Mountain of Motor Development Metaphor}

The third phase in the Gallahue's hourglass model is fundamental movement phase and in the Clark and Metcalfe's the mountain of motor development metaphor is fundamental patterns period. Fundamental movement patterns are basic observable patterns of behavior. Locomotor activities such as running and jumping, manipulative activities such as throwing and catching, and stability activities such as the beam walk and one-foot balance are examples of fundamental 
movements that should be developed during the early childhood years. The conditions of the environment (opportunities for practice), encouragement, instruction, and the ecology (context) of the environment play important roles in the degree to which fundamental movement skills develop. In performance and learning of abilities and movement patterns, there are age-related differences. Some experimenters have examined and confirmed age-related differences in the performance and learning of motor skills (for example, Salehi et al., 2016; 2017). Gallahue view the entire fundamental movement phase as having separate but often overlapping stages: the initial stage, the emerging elementary stages, and the proficient stage.

The initial stage of a fundamental movement phase represents the child's first goal-oriented attempts at performing a fundamental skill. Movement is characterized by missing or improperly sequenced parts, markedly restricted or exaggerated use of the body, and poor rhythmical flow and coordination. The spatial and temporal integration of movement is poor. Typically, the locomotor, manipulative, and stability movements of the 2 - 3-year-old are at the initial level. Some children may be beyond this level in the performance of some patterns of movement, but most are at the initial stage. The emerging elementary stages, includes 4 to 5 years, and on which there may be several, involve gaining greater motor control and rhythmical coordination of fundamental movement skills. The synchronization of the temporal and spatial elements of movement is improved, but patterns of movement during these stages are still generally restricted or exaggerated, although better coordinated. The proficient stage within the fundamental movement phase is characterized by mechanically efficient, coordinated, and controlled performances. Proficient fundamental movement skills are mature in these three process aspects. With continued opportunities for practice, encouragement, and instruction they will, however, continue to improve in terms of the product components of how far, how fast, how many, and how accurately. The majority of available data on the acquisition of fundamental movement skills suggests that children can and should be at the proficient stage by age 5 or 6 in most fundamental skills. Although some children may reach this stage primarily through maturation and with a minimum of environmental influences, the vast majority require some combination of opportunities for practice, encouragement, and instruction in an environment that fosters learning (Gallahue, Ozmun, \& Goodway, 2012).

Clarke and Metcalfe in the description of fundamental patterns period, through similar concepts have stated that the fundamental movements begin during infancy, but will endure throughout childhood for most children. As in all periods of the mountain of motor development, many factors affect the rate and breadth of acquisition of movement skills. For example, some children may have ample opportunity to experience a variety of movements. Some may even have the luxury of high-quality instruction supplemented by appropriate amounts and types of practice. Others may have limited chance to partake in such activities, thus making the ascent up the mountain more arduous. This period of de- 
velopment includes fundamental locomotor skills, such as walking, running, hopping, jumping and etc., and fundamental object-control skills that Clark and Metcalfe (2002) subdivide it into object projection (such as throwing, kicking) and object interception (such as catching, trapping). Both types of movement require increasing levels of interaction between the environment and the mover.

These abilities are all a function of skills developed in previous periods of the ascent up the mountain (growing and progress in motor skills development). This period of development also includes fine motor manipulation, include cutting with scissors, handwriting, drawing, eating (for instance, use of spoons or chopsticks), or playing certain musical instruments (for example, playing piano or guitar). Here again, achievement in this area is greatly affected by experiences and accomplishments earlier on the "mountain", in the reflexive and preadapted periods. Fundamental patterns period are essential and establishes the basis for future movement endeavors. Hence, skill developed at this point of the journey up the mountain can be considered "base camp", to which the performer may want or need to return from time to time (Clark \& Metcalfe, 2002).

According to what was said, it seems fundamental patterns period in the mountain of motor development metaphor are adaptable with fundamental movement skills in Gallahue's hourglass model and reflect the same concepts, so that both Clarke and Metcalfe and Gallahue introduce fundamental movements as basis for future skills that used in throughout life. In one hand, Gallahue state that failure to offer opportunities makes it exceedingly difficult for an individual to achieve proficiency in fundamental movement skills and will inhibit further application and development in the specialized movement phase, so that there is "proficiency barrier" between fundamental movement skills and their companion specialized sport skills. On the other hand, Clark \& Metcalfe (2002) suggested that fundamental motor skills provided the "basecamp" to the mountain of motor development leading to motor skillfulness.

\section{The Fourth Period of the Gallahue's Hourglass Model and Clark and Metcalfe's the Mountain of Motor Development Metaphor}

In the mountain of motor development metaphor, the fourth period has been called context-specific period and in the hourglass model has been called specialized movement phase. In Gallahue's hourglass model, the specialized movement phase is a period when fundamental stability, locomotor, and manipulative skills are progressively refined, combined, and elaborated upon for use in increasingly demanding situations, for example, for daily living, recreation, and sport pursuits. According to Gallahue, Ozmun, \& Goodway (2012), the onset and extent of skill development within the specialized movement phase depends on a variety of task, individual, and environmental factors. Reaction time and movement speed, coordination, body type, height and weight, customs, culture, peer pressure, and emotional makeup are but a few of these constraining factors. The spe- 
cialized movement phase has three stages consists of transitional stage, application stage and lifelong utilization Stage.

Somewhere around their seventh or eighth year, children commonly enter a transitional movement skill stage (Haubenstricker \& Seefeldt, 1982). During the transitional period, the individual begins to combine and apply fundamental movement skills to the performance of specialized skills in sport and recreational settings. Walking on a rope bridge, jumping rope, and playing kickball are examples of common transitional skills. Transitional movement skills contain the same elements as fundamental movements with greater form, accuracy, and control. Gallahue, Ozmun, \& Goodway (2012) argue that fundamental movement skills developed and refined during the previous stage are applied to play, game, and daily living situations. Transitional skills are applications of fundamental movement patterns in somewhat more complex and specific forms. This stage is an exciting time for the parent and the teacher as well as for the child. Children are actively involved in discovering and combining numerous movement patterns. Parents, teachers, and youth sport coaches during this stage should help children increase their motor control and movement competence.

Application stage, includes the age of 10 to 13 years old. During the In the application stage, increased cognitive sophistication and a broadened experience base enable the individual to make numerous learning and participation decisions based on a variety of task, individual, and environmental factors. In this stage, individuals begin to seek out or to avoid participation in specific activities. Increased emphasis is placed on form, skill, accuracy, and the quantitative aspects of movement performance. This is a time for more complex skills to be refined and used in advanced games, lead-up activities, and selected sports.

The lifelong utilization stage of the specialized phase of motor development begins around age 14 and continues through adulthood. The lifelong utilization stage represents the pinnacle of the process of motor development and is characterized by the use of one's acquired movement repertoire throughout life. The interests, competencies, and choices made during the previous stage are carried over, further refined, and applied to a lifetime of daily living, recreational, and sports-related activities. Factors such as available time and money, equipment and facilities, and physical and mental limitations affect this stage. Among other things, one's level of activity participation will depend on talent, opportunities, physical condition, and personal motivation. In essence, the lifelong utilization stage represents a culmination of all preceding stages and phases. It should, however, be viewed as a continuation of a lifetime process. Specialized skill development can and should play a role in our lives, but it is unfair to require children to specialize in one or two skill areas at the expense of developing their movement repertoire in and appreciation for many other areas (Landers, Carson, \& Tjeerdsma-Blankenship, 2010).

Clark and Metcalfe (2002) in describing the context-specific period stated that once the individual has arrived at the "base camp of movement" and has established a solid repertoire of fundamental movement skill, opportunities arise 
for expanding the movement repertoire into more varied and advanced movements by combining and varying the fundamental movement patterns to adapt to new and different movement situations. Because movement can take on so many new and different forms at this time of life, the mountain of motor development (see Figure 2) begins to split into several different peaks, with each leading to the apex of development for different movement skills. Individuals may begin to branch off onto other peaks, or even seek to climb several, as they "experiment" with different kinds of movement. They have not decided which ones, if any, they will want to pursue on a longer-term basis, or if they would like to try to develop further skill, even to excel. Individual may participate in some activities for several years, thus ascending several different peaks on the mountain, until they decides that one of these sports is his favorite, and that is where he wants to dedicate his time and effort. Thus, he will descend one or more of the peaks as he continues to ascend another. As a result of any number of life experiences, individual may achieve considerable height on a climb up the mountain, only to regress or return to lower levels. Perhaps they may leave one peak all together as they begin the ascent up another. This period is one that is experienced by most, if not all, people. However, the next period of the mountain can be somewhat more exclusive (Clark \& Metcalfe, 2002; Payne \& Isaacs, 2011).

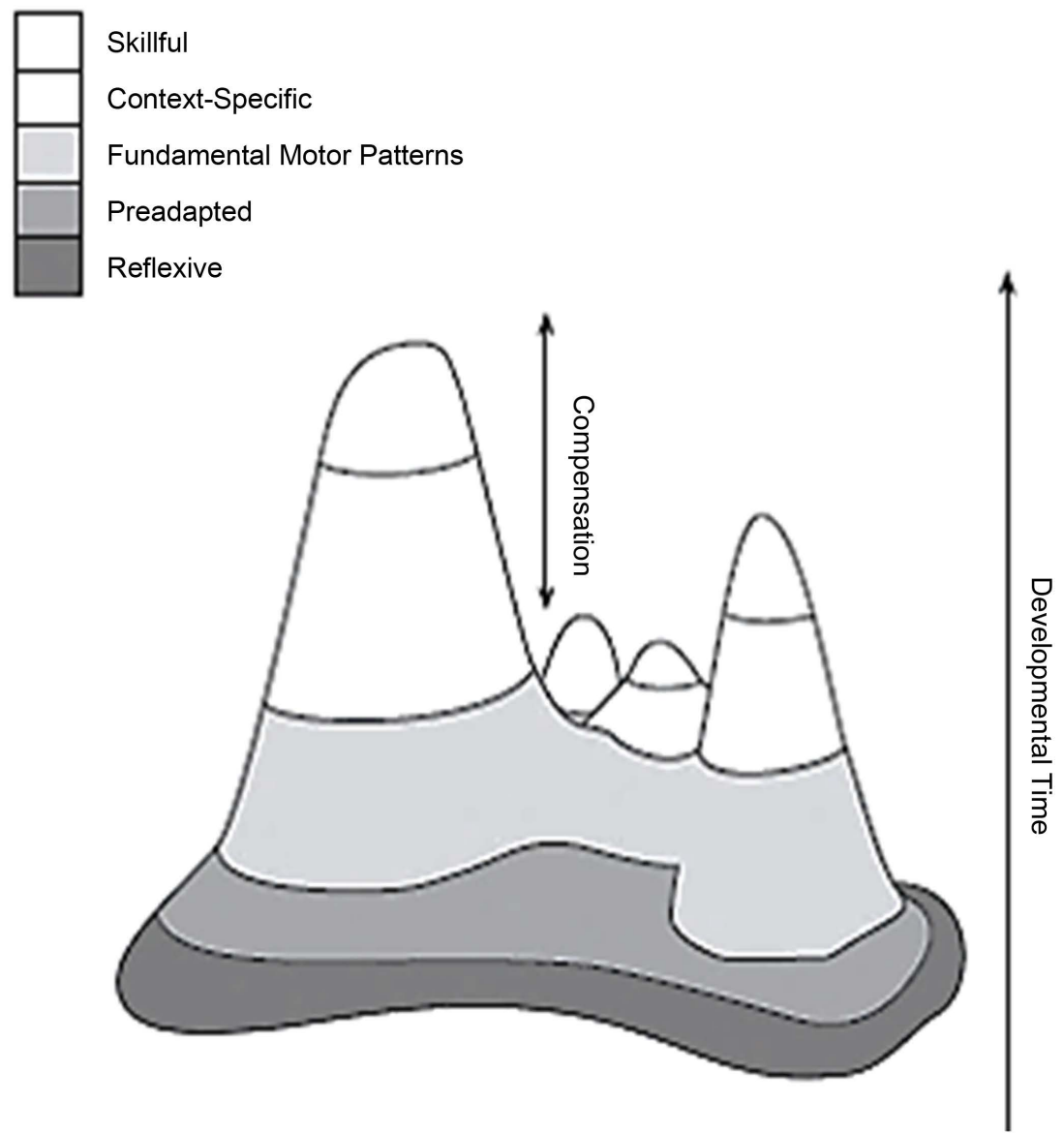

Figure 2. The mountain of motor development (Clark \& Metcalfe, 2002). 
It seems Clark and Metcalfe (2002) implicitly refers to the two levels of specialized movements in hourglass model including the transfer and application, by expressing that individual may participate in some activities for several years, thus ascending several different peaks on the mountain, until he decides that one of these sports is his favorite, and that is where he wants to dedicate his time and effort. This is because at transitional stage, individual regardless of abilities willing to participate in a variety of activities and so, has a chances of success in a few fields (climb to several peak), until based on the interests and abilities prefers a particular sport and works in it (application stage). During the application stage, individuals begin to seek out or to avoid participation in specific activities. Increased emphasis is placed on form, skill, accuracy, and the quantitative aspects of movement performance. This is a time for more complex skills to be refined and used in advanced games, lead-up activities, and selected sports.

\section{The Fifth Period of the Clark and Metcalfe's the Mountain of Motor Development Metaphor and Matching It on the Hourglass Model}

The fifth period of the Clark and Metcalfe's the mountain of motor development has been called the skillful period. The goal of this period is the achievement of skillful behavior. Motor skill is characterized as being voluntary, efficient and adaptive (Clark, 1995). According the Clark and Metcalfe (2002), the attainment of the skillful period of development requires both experience and practice. This level of motor development is also influenced by the previous period whereby having a broad-based and well-developed supply of movement skills will assist in the development of higher levels of skill in this period. This skillful period is not achieved by all, and it is intentional, a level of attainment based on months or years of dedication toward proficiency in one or more areas of human movement. Having achieved this period is indicative of some degree of proficiency in a specific movement skill or skills.

Attainment of this higher level of proficiency or expertise is often assessed by one's ability to perform the movements involved with less concentration, enabling the performer to instead pay attention to strategies or adaptations of the movement during the performance. These higher levels of proficiency in movement are attained through greater motivation to excel. That motivation may come from one's family, the childhood neighborhood, or cultural background. It may arise out of geographic or peer pressure or incentives that ultimately affect one's interest level, amount and quality of coaching or instruction, and practice.

Another factor affecting our ability to become skillful movers is our personal physiology. Physiological factors like our height, weight, strength, endurance, and flexibility affect skillfulness. We can certainly improve some of these factors through physical training. However, regardless of motivation, opportunity, instruction, and practice, some individuals will simply never attain the level attained by others, or it may take them longer and require more hours of work. In other words, their ascent up the peak may be more arduous. In addition, there is 
a limit to the number of skills in which any one person can become skillful. We have all seen examples of the rare individuals who have become professional athletes in more than one sport-achieving that level of skillfulness on more than one peak is rare. There are many different skills, or different peaks to ascend, and most of us will attempt to ascend fewer peaks and will ascend to lower levels than the multisport professional athlete. In short, the development of skillfulness is the result of gradual, sequential, progressive refining of movement ability over a relatively long period of time (Clark \& Metcalfe, 2002). However, even if such a high level is attained, it cannot be maintained forever.

Given that in fifth period of the Clark and Metcalfe's the mountain of motor development is argued that the attainment of the skillful period of development requires both experience and practice, and factor factors such as physiological factors, and personal motivation affect this period, hence it seems skillful period in the mountain of motor development is equal to the lifelong utilization stage in hourglass model and reflect the similar concepts. Because essentially, the lifelong utilization stage represents a culmination of all preceding stages and phases and in Clark and Metcalfe's the mountain of motor development referred to this issue explicitly. Skillful movement is characterized by efficiency, adaptability, and certainty of outcome. To be skillful, a performer must move with biomechanical, psychological and physiological efficiency. While being consistent, the skilled performer must also maintain the adaptability to adjust when conditions change. This is referring to the stage that is the culmination of all stages and phases (lifelong utilization stage).

\section{The Sixth Period of the Clark and Metcalfe's the Mountain of Motor Development Metaphor and Matching It on the Hourglass Model}

The last period on the mountain of motor development involves compensation. Compensation is generally considered to be a nullifying of or adapting to the effects of some type of negative influence. Clark and Metcalfe note two types of compensation in particular, that evolving from injury and that evolving from the declines seen with aging in middle to late adulthood. Injury can occur at any time throughout life. The effects of injury can be permanent and affect our ability to continue the climb to a higher plateau. In fact, injury often results in a regression to a previous period of development or "level" on the mountain. Nevertheless, we humans are adaptable and can overcome the adversity experienced with the injury and resume the climb, often attaining higher levels than ever before. Imagine the plight of an elite athlete who suffers a severe knee injury. Initially the athlete ceases all participation in the sport and may undergo surgery, followed by physical therapy. Slowly, she may return to play, may achieve her former skill level, and may even surpass that level-achieving full and successful compensation. However, she may have been so severely injured that she cannot regain her former ability and may not even be able to return to play at all (Payne \& Isaacs, 2011). 
Most of the typical declines (such as slowing, reduction in strength, endurance, flexibility) that occur with aging can be compensated through education, training and taking appropriate activities. Nevertheless, some decline with aging appears to be inevitable. We can, however, adapt to these declines, and often we can overcome them for a period of time. Just like with injury in earlier periods of life, we can adapt to the changes that come with aging, redirect our efforts, and regain a very functional status. In other words, we can resume our climb up the mountain following a return to a lower level, maybe even all the way down to the base camp. Once we have resumed that climb, we may attain heights for a while that we had never before attained. In short, our motor development during later adulthood does not have to be a slow and systematic decline. It can be replete with numerous periods of progression. Imagine an older adult who has gone years without participating in any form of vigorous activity. Following a less than positive medical checkup, he decides to gradually begin exercising by walking. After a period of time he decides to slowly start jogging. As described throughout this book, that physical activity will likely show widespread benefit physically, socially, emotionally, and even intellectually. However, after the initial improvements in fitness, the jogger decides to stop jogging and take up softball with a local league for older adults. He resumed his climb up one peak, came back down, and started up another, a common and expected life change that is accounted for by the mountain of motor development metaphor (Table 1).

Clark and Metcalfe in the sixth period of the mountain of motor development also have pointed to the part of lifelong utilization stage in hourglass model. These authors to describe the ups and downs of motor behavior have used the concept of compensation. This issue is also stated in the hourglass. According to Gallahue, at some point, the hourglass turns over .The timing of this occurrence is variable and often depends more on social and cultural factors than on physical and mechanical factors. For most individuals, the hourglass turns over and the "sand" (i.e., the stuff of life) begins to pour out during the late teens and early 20s for various reasons such as work, occupation or lack of physical activity. Time restrictions limit the pursuit of new movement skills and the maintenance of skills mastered during childhood and adolescence. The sand falls through two different filters including hereditary and lifestyle filter. The hereditary filter is going to be either dense, causing the sand to filter through slowly, or easy to penetrate, allowing the sand to flow through more rapidly. Sand that has fallen through the hereditary filter cannot be recovered, but it must pass through a second, or final, filter called the lifestyle filter. The density of the lifestyle filter is determined by such things as physical fitness, nutritional status, diet, exercise, the ability to handle stress, and social and spiritual well-being. The lifestyle filter is environmentally based, and we have a good deal of control over the rate at which sand falls through this filter. Although we can never stop sand from flowing to the bottom of the hourglass, we can slow down the rate at which it falls. We can directly influence how fast sand falls through our hourglasses. As teachers, coaches, therapists, and parents we have the wonderful opportunity to sho- 
Table 1. Matching the Gallahue's hourglass model and the mountain of motor development.

$\left.\begin{array}{ccc}\hline \text { Gallahue's hourglass model } & \text { Subdivisions } & \text { Mountain of motor development } \\ \hline \text { Reflexive movement phase } & \begin{array}{c}\text { Information encoding stage } \\ \text { Information decoding stage } \\ \text { Reflex inhibition stage } \\ \text { Pudimentary movement phase }\end{array} & \text { Reflexive period } \\ & \text { Initial stage } & \text { Preadapted period } \\ \text { Fundamental movement phase } & \text { Emerging elementary stage } & \text { Fundamental patterns period } \\ \text { Specialized movement phase } & \text { Proficient Stage } \\ & \text { Transitional stage } \\ \text { Application stage } & \text { Lifelong utilization stage }\end{array}\right\}$

vel "sand" into many "hourglasses". We also have the privilege and the obligation to help others develop "lifestyle filters" that will slow the rates at which sand falls in their hourglasses. Sand can still be added even when hourglasses are overturned and the sand is falling to the bottom. Each of us has lifelong opportunities for learning. By taking advantage of the numerous opportunities for continued development and physical activity, we can add more sand and improve the quality of life (Gallahue, Ozmun, \& Goodway, 2012). It seems, this similar to the concept of compensation that has been proposed in the mountain of motor development.

\section{Discussion}

This study compared the Gallahue's hourglass model and Clark and Metcalfe's the mountain of motor development metaphor. David Gallahue presented a model using ecological perspective, in which process and product of motor development are likened to an inverted hourglass. In this model, stages and levels of development of motor development are described and explained accurately. Hourglass model conceptualize both the descriptive products (hourglass) and explanatory processes (inverted triangle) of motor development as it typically unfolds across the life span. Clark and Metcalfe also examined described and justified motor development using a metaphor that called the mountain of motor development. The distinctive features of both the hourglass model and Clark and Metcalfe metaphor are describing and explaining motor development simultaneously. Gallahue divided motor development process into four stages and Clark and Metcalfe divided those into six periods. Each of the periods of motor development in Clark and Metcalfe's the mountain of motor development can be considered as one of the stages or part of a specific stage in the Gallahue's hourglass model. Thus, it seems that the hourglass model is more comprehensive.

Both theoretical frameworks begin with reflexive movements and finish with specialized and skilled movements. In the Gallahue's hourglass model they referred to the reversal of the hourglass and performance degradation in adult- 
hood. Of course, this is assumed to be different from one person to another and the destruction becomes slower by changing lifestyle and tendency to physical activity. Clarke and Metcalfe for explaining this, have used the concept of compensation.

Motor development in the hourglass model is a discontinuous process, that is, a process that, although phase-like and stage-like in a general sense, is highly variable in a specific sense. Motor development when viewed to be discontinuous is in effect a dynamic (i.e., nonlinear) process occurring within a self-organizing system (i.e., the "hourglass"). On the other hand, Gallahue believes that "Real" hourglasses occur in both time and space. They are multidimensional and as such contain, along with the motor domain, both cognitive and affective domains as well. As a result, real hourglasses have height, width, and depth and must be supported if they are to remain upright. In other words, the triangulated hourglass model is more than a motor model. It is a model of motor development that influences, and is influenced by a wide variety of cognitive and affective factors operating within both the individual and the environment. Thus, the triangulated hourglass model shape can be consistent with many different cultural situations. And its validity and reliability have been examined in many countries such as America, Canada, Australia and Brazil. For example, O'Keeffe studied the relationship between fundamental movement skills and sport-specific skills in a test of the Triangulated Hourglass Model of motor development. The results of his investigation led him to conclude that "this study provides empirical evidence in support of Gallahue's theoretical model with respect to the relationship between fundamental skill and sport-specific skill phases and also for dynamical systems theory to explain the learning process" (O’Keeffe, 2001, abstract). This model also has weaknesses that have been eliminated during a time. For example, when in the late 1970s, this model was published for the first time, it only included hourglass and did not have inverted triangle. But when in 1982 an article was published by Kugler, Kelso and Turvey where dynamic system was introduced to people (Kugler, Kelso, \& Turvey, 1982), Gallahue re-think the hourglass, because this model is not consistent with the principles of dynamic systems and was criticized. Therefore, Gallahue added to it the inverted triangle, so that, now the hourglass, includes both aspects of description (hourglass) and explain (inverted triangle) of motor development.

Clarke and Metcalfe also with taking advantage of the Gallahue hourglass model, in an effort to provide a fairly complete and simple picture of the features and principles and growing motor systems, introduced integrated metaphor of the mountains of motor development. This metaphor is one of the most recent depictions of human motor development that combines a description of the expected changes in motor development with explanations about how these changes may ensue. In this metaphor, on basis dynamic systems (Newell, 1986), motor development is seen as the result of a process in which changing constraints (organismic, environmental, and task) interact and self-organize yielding a cumulative and sequential pattern of developing motor skills. 
Clarke and Metcalfe state that while this metaphor is useful as a heuristic device to facilitate an understanding of motor development, it is important to remember that metaphors are not to be ends unto themselves. Metaphors are first steps in building towards more formalized models and theoretical frameworks and are to be assessed on the criteria of usefulness. Certainly, if the mountain provides an intuitive and accurate means to communicate knowledge about motor development and thus, facilitates teaching and learning, then on one level we have been successful in our intent. Clarke and Metcalfe metaphor, is not only one of the newest descriptions of human motor development, but also usable for everyone, even those who have experienced some form of abnormal development. Because the process is embodied by mountains, it can be applied for any human, typical or atypical. While some may have to climb a different mountain than most, their path up that mountain will be the result of the same process (Clark \& Metcalfe, 2002). That is, the constraints may differ and the limitations may be harder to circumvent, but the developmental products will result from interaction between the individual, environment and the task.

Overall, the Gallahue's hourglass model and Clark and Metcalfe's conceptual metaphor, which are provided on the basis of dynamic systems, have a large overlap and are important to facilitate understanding and provide a theoretical framework of the process and product of motor development.

\section{References}

Clark, J. E. (1995). On Becoming Skillful: Patterns and Constraints. Research Quarterly for Exercise and Sport, 56, 173-183. https://doi.org/10.1080/02701367.1995.10608831

Clark, J. E., \& Metcalfe, J. S. (2002). The Mountain of Motor Development: A Metaphor. In J. E. Clark, \& J. Humphrey (Eds.), Motor Development: Research and Reviews (pp. 163-190). Reston, VA: NASPE Publications.

Gallahue, D. L. (1998). Motor Development: A Descriptive and Analytic Perspective. In R.J. Krebs, F. Copetti, \& T.S. Beltrame (Eds.), Discutindo o desenvolvimento infantile (pp. 65-90). Santa Maria: Sociedade Internacional Para Estudoes Da Crianca (SIEC).

Gallahue, D. L., Ozmun, J. C., \& Goodway, J. (2012). Understanding Motor Development: Infants, Children, Adolescents, Adults. New York: McGraw-Hill.

Haywood, K. M., \& Getchell, N. (2014). Lifespan Motor Development (6th ed). Champaign, IL: Human Kinetics.

Kugler, P. N., Kelso, J. A. S., \& Turvey, M. T. (1982). On the Control and Coordination of Naturally Developing Systems. In J. A. S. Kelso, \& J. E. Clark (Eds.), The Development of Movement Control and Coordination (pp. 25-36). New York: Wiley.

Landers, R. Q., Carson, R. L., \& Tjeerdsma-Blankenship, B. (Eds.). (2010). The Promises and Pitfalls of Sport Specialization in Youth Sport. Journal of Health, Physical Education, Recreation, 3, 14-21.

Newell, K. M. (1986). Constraints on the Development of Coordination. In M. G. Wade, \& H. T. A. Whiting (Eds.), Motor Development in Children: Aspects of Coordination and Control (pp. 341-361). Amsterdam: Nijhoff. https://doi.org/10.1007/978-94-009-4460-2_19

O'Keeffe, S. I. (2001). The Relationship between Fundamental Motor Skills and Sport Specific Skills: Testing Gallahue's Theoretical Model of Motor Development. Unpub- 
lished Doctoral Thesis. Ireland: University of Limerick.

Payne, V. G., \& Isaacs, L. D. (2011). Human Motor Development: A Lifespan Approach (8th ed). New York: McGraw-Hill.

Salehi, S. K., Sheikh, M., Hemayattalab, R., \& Humaneyan, D. (2017). The Effect of Age-Related Changes and Explicit and implicit Awareness on Mixed Motor Sequence Learning and Its Consolidation. Journal of Research in Rehabilitation Sciences, 12, 13-19.

Salehi, S. K., Sheikh, M., Hemayattalab, R., \& Humaneyan, D. (2016). The Effect of Different Ages Levels and Explicit-Implicit Knowledge on Motor Sequence Learning. International Journal of Environmental \& Science Education, 18, 13157-13165.

Seefeldt, V., \& Haubenstricker, J. (1982). Patterns, Phases, or Stages: An Analytic Model for the Study of Developmental Movement. In J. A. S. Kelso, \& J. E. Clark (Eds.), The Development of Movement Control and Coordination (pp. 309-318). New York: Wiley.

Submit or recommend next manuscript to SCIRP and we will provide best service for you:

Accepting pre-submission inquiries through Email, Facebook, LinkedIn, Twitter, etc. A wide selection of journals (inclusive of 9 subjects, more than 200 journals)

Providing 24-hour high-quality service

User-friendly online submission system

Fair and swift peer-review system

Efficient typesetting and proofreading procedure

Display of the result of downloads and visits, as well as the number of cited articles Maximum dissemination of your research work

Submit your manuscript at: http://papersubmission.scirp.org/

Or contact ape@scirp.org 